\title{
LA REALIDAD SOCIAL COMO REALIDAD Y APARIENCIA
}

\section{Miguel Beltrán}

El tema de la apariencia y la realidad, que tiene una larga tradición filosófica, es a mi modo de ver capital para acotar el objeto de la Sociología, la realidad social. El término apariencia viene definido en el Diccionario de la Real Academia como "aspecto o parecer exterior de una persona o cosa» (primera acepción), y como «cosa que parece y no es» (tercera acepción). Es curioso observar cómo el Diccionario se orienta decididamente por la vía de oponer apariencia a realidad, bien señalando que la primera no ofrece sino el aspecto exterior de las cosas (es decir, que ofrece sólo un aspecto de la cosa, que es parcial), bien que parece y no es (es decir, que es engañosa). Y digo que es curiosa esta orientación porque ignora otra acepción del término, neutra y etimológicamente correcta, que define la apariencia como la manifestación de la cosa, identificando apariencia y realidad. Bien es verdad que el uso del término apariencia es predominantemente desconfiado: la apa. riencia es sólo el aspecto externo de la cosa, una visión por tanto que oculta nada menos que «lo interior», lo que la cosa es «en realidad»; parcialidad, pues, que se resuelve en engaño («las apariencias engañan», dice la sabiduría popular): apariencia y realidad son cosas diferentes en la medida en que la primera oculta a, y desorienta sobre, la segunda.

Acabo de decir que, desde este punto de vista, apariencia y realidad son cosas diferentes: esto no es completamente exacto, pues no siempre se entiende la apariencia como cosa en el mismo sentido en que se valora la realidad como cosa; con 
frecuencia se considera que la eventual discrepancia no se da entre dos cosas (la apariencia y la realidad), sino entre una cosa (la realidad) y su apariencia, su modo de manifestarse. Adelantaré ya que, para lo que aquí interesa, entiendo que la apariencia es apariencia engañosa, y que tan cosa es la apariencia como la realidad que deforma, oculta o enmascara.

Señala Ferrater $(1979: 175)$ que la necesidad de distinguir entre apariencia y realidad tiene al menos dos motivos. En primer lugar, hay realidades que a primera vista se manifiestan o parecen de un modo, pero que una vez examinadas con más atención o de manera más ilustrada resultan ser de otro modo que como se dejan ver. En segundo lugar, el saber acerca de las cosas equivale a dar una explicación de ellas, y esto implica dar razón de cómo y por qué aparecen como lo hacen, especialmente cuando lo hacen de una manera engañosa, al menos a primera vista. Debe hacerse notar que es la apariencia la que es engañosa (cuando lo es), no el testimonio de los sentidos; no quiero decir que los sentidos no se engañen nunca, sino que las apariencias no son meras ilusiones: en el caso del palo sumergido en agua los sentidos testimonian correctamente que parece quebrado, y no se engañan al apreciarlo así; ciertamente, el palo no está quebrado, pero las leyes de la refracción así lo presentan. Pues bien, con este ejemplo, que tomo de Ferrater, queda claro que la apariencia es también propiamente real (tan real como la cosa misma, aunque de un tipo de realidad diferente: apariencial), no ilusoria; esto es, no dependiente de la debilidad de los sentidos, y necesitada por tanto de una explicación.

Más arriba indicaba que, para los efectos de estas páginas, la apariencia es apariencia engañosa. Es evidente, sin embargo, que esto no es siempre así, pues hay apariencias que no engañan, que son idénticas a la cosa, la cual se manifiesta o aparece tal como es. Pero las apariencias usinceras" pueden dejarse tranquilamente de lado en este momento, ya que no plantean problema alguno. Mejor dicho, plantearán una seria dificultad a quienes piensen que las cosas sólo son accesibles por su apariencia, y adopten ésta como única vía de revelación o mostración de la cosa: pues no hay según digo un solo tipo de apariencias, sino dos, las engañosas y las que he llamado sinceras. Una posición fenoménica o empírica a ultranza habrá de sostener que no tiene sentido distinguir entre apariencia y realidad, y las identificará. Con lo que, según creo, privilegiará indebidamente las apariencias engañosas, otorgándoles el mismo estatuto que a las realidades que se muestran tal cual son y en las que coincide sin más dificultad su ser con su parecer. Pues bien, las apariencias de las que aquí hablaré son aquellas que guardan una mayor o menor diferencia con la cosa.

Esa apariencia diferente de la realidad en cierto modo revela la cosa, y en cierto modo la oculta. La revela, en efecto, porque la apariencia es el modo que esa cosa tiene de mostrarse, de hacerse visible, bien que de manera distorsionada. Y la oculta también, en la medida en que presenta la cosa como no es, de manera infiel a la realidad. La apariencia, pues, supone un juego de revelación y ocultación de la realidad que exige habérselas con ella para llegar a la cosa, y para dar razón de por qué la cosa es así y su apariencia es de esta otra manera. 
La tradición filosófica que distingue entre apariencia y realidad es sobre todo idealista. Ejemplo necesario es el de Kant, quien considera a las apariencias únicamente como representaciones, no como cosas; bien es verdad que Kant distingue entre la cosa en sí o nóumeno, el fenómeno, y la apariencia; el nóumeno es teóricamente incognoscible, el fenómeno manifiesta propiedades que son de la cosa en sí y es objeto de experiencia, en tanto que la mera apariencia es ilusoria o engañosa. Así, pues, el fenómeno es una realidad innegable accesible a la experiencia, en tanto que la apariencia, por ser ilusoria, ha de ser negada. Pero no es obviamente la ocasión de adentrarse en tal construcción: baste para el objeto de estas páginas con dejar anotado lo que antecede, y valga la licencia de simplificar tan desconsideramente a Kant.

Dejando aparte la distinción tripartita kantiana y continuando con la dicotomía de, por un lado, apariencia o fenómeno y, por otro, realidad de la cosa, el tema puede remontarse muy atrás. En Platón, por ejemplo. el mundo de los fenómenos es el de las meras representaciones, fantásmata o apariencias. Sólo los seres son seres, y sus apariencias - el mundo fenoménico que percibimos- no son sino representaciones. Se considera, pues, separado y diferente el mundo de las apariencias del de la realidad, y se piensa que sólo se tiene acceso inmediato al primero, mundo de sombras proyectado por la luz de la realidad. Pero el problema del mundo fenoménico y su relación con el mundo real ha sido objeto de permanente atención filosófica, dando origen a posiciones muy diferentes: desde un fenomenismo radical que niega cualquier realidad tras el fenómeno, y para el que «ser es ser percibido", hasta la fenomenología, o teoría de los fenómenos puros en expresión de Husserl, para quien los fenómenos son «lo intuitivo como tal»: un asunto que concicrne a la conciencia pura encerrada en el círculo inmanente de lo dado. Ese centrarse en el fenómeno, en lo dado, que caracteriza a la fenomenología husserliana, tiene algo en común incluso con posiciones como la de las llamadas por la filosofía de la ciencia físico-natural «teorías fenomenológicas» o «de la caja negra»: se trata de teorías puramente observacionales que no aspiran a ofrecer ninguna descripción de los mecanismos que producen los fenómenos estudiados, en contraste con las «teorías representacionales» o «de la caja traslúcida», que intentan describir los mecanismos reales o procesos «internos» al fenómeno que se estudia, por hipotéticos que hayan de ser.

Pero me temo que incluso tan sumaria referencia a algunos de los más notorios tratamientos filosóficos del tema de la apariencia y la realidad pueda desenfocar mi propósito. Debe quedar meridianamente claro que no intento en modo alguno plantear un problema ontológico, sino epistemológico, y aun ello en sentido lato. Por consiguiente, nada más lejos de mis intenciones que establecer familiaridad alguna con el ser o con la cosa en sí, sean uno y otra lo que fueren. Me limito a señalar que en ciertas ocasiones las cosas (objetos, estados, situaciones, procesos) se presentan al observador tal y como son, y en otras, por el contrario, a través de una apariencia que en alguna medida las deforma o disfraza.

$E$ insisto en que el problema puede calificarse, aunque con relativa impreci- 
sión, de epistemológico, pues lo planteo como básico para el acotamiento del objeto de conocimiento de una ciencia, la Sociología. Mi pregunta, pues, no versa sobre qué sea la realidad (social): no es una pregunta sobre el ser (una pregunta ontológica), sino sobre qué objetos ha de tener en cuenta un conocimiento que quiera dar razón de la realidad social (una pregunta, pues, epistemológica). Y adelanto como respuesta que han de tenerse en cuenta tanto realidades como apariencias, por las razones que después se verán. Soy consciente de lo rudimentario de mi lenguaje y de la falta de precisión técnico-filosófica de que adolece; espero, sin embargo, ser disculpado en atención a la modestia de mi propósito.

En resumen, y habida cuenta de que la realidad social puede manifestarse en unas ocasiones tal como es y en otras a través de apariencias engañosas, creo que son posibles al respecto tres posiciones muy diferentes entre sí. Para la primera, de una cierta ontofilia, lo que importa es la cosa (estado, situación, proceso, objeto) en su ser más real: la apariencia o fenómeno, en la medida en que es engañoso, no es sino pura representación, mera ilusión que hay que superar y despreciar para llegar a la realidad de la cosa; si la cosa está enmascarada, lo que procede es desenmascararla y atenerse exclusivamente a ella tal como es en realidad. Una segunda posición, fenomenalista, valoraría la representación o fenómeno como única realidad, en contra de cualquier presunta realidad de la cosa, negando todo sentido a la afirmación de que existan diferencias entre realidad y apariencia; lo que existe es lo que parece existir. El fundamento posible de esta segunda posición sería, o bien la afirmación de que no hay nada que pueda ser llamado realidad en sí, una realidad oculta por las apariencias, o bien que de existir se trataría de algo incognoscible, inaccesible a la observación y al conocimiento.

La tercera posición, en cambio, parte del hecho de que efectivamente «las cosas - - algunas de ellas- no son lo que parecen»; cuando se da tal diferencia entre la realidad y su apariencia, ambas son «reales»: ambas, por así decirlo, forman parte de la realidad. Esta incluye, por tanto, a la realidad-real (la cosa como es en realidad) y a la realidad-apariencia (la cosa tal como se presenta), y el conocimiento de la realidad -en sentido amplio- implica el de la cosa como es - realidad en sentido estricto- y el de su apariencia - apariencia engañosa-. Y esto es así porque tanto la cosa como es (accesible sólo a través de un proceso de desenmascaramiento), como su apariencia o máscara producen efectos en el resto de la realidad: ambas, realidad y apariencia, son, por así decirlo, reales en sus efectos.

Conviene indicar que cuando empleo expresiones como «la cosa como es» no me refiero a ninguna realidad, digamos, metafísica, a ningún ser-en-sí de orden nouménico o esencial. «La cosa como es», «la realidad de la cosa» como algo distinto de su apariencia, es también en cierto modo algo fenoménico, aunque no inmediatamente perceptible por estar recubierto de una apariencia engañosa. En ocasiones tal apariencia podrá ser salvada por segundas o sucesivas aproximaciones más cuidadosas o ilustradas, pero otras veces lo será tan sólo por la vía de la reconstrucción racional de lo que hay debajo del fenómeno. Pero «salvar las apariencias» no es para mí superarlas y dejarlas aparte: interesa tanto la cosa como su apariencia, 
y muchas veces ésta más que aquélla; una y otra, como más arriba se apuntaba, son "cosas", ambas constituyen objeto de conocimiento, y ambas, por tanto, requieren ser descritas y explicadas. Esta tercera posición es la que defiendo en estas páginas, y entiendo que está tan alejada del ontologismo de la primera, orientada a la cosa-en-sí, como del empiricismo de la segunda, interesada sólo en el fenómeno. Entiendo que la tercera posición es a la vez empirista y racionalista, pragmática en el sentido de que no muestra interés por planteamientos ontológicos y sí por los efectos del objeto, y no idealista, porque no es en el sujeto cognoscente en el que encuentra respuesta a sus preguntas, sino en el objeto y sus eventuales apariencias engañosas.

Es la propia realidad la que se manifiesta a través de apariencias, engañosas o no. Pero no es sólo de la realidad de quien proceden las apariencias: no es ella la única productora de su disfraz, sino que los mismos observadores la disfrazamos constantemente. Si vivimos en un mundo de apariencias, y con frecuencia de apariencias engañosas, en buena medida ello es obra nuestra. En efecto, y como justamente indica Hannah Arendt, «los clichés, las frases hechas, la adhesión a lo convencional, los códigos estandardizados de expresión y conducta tienen la función socialmente reconocida de protegernos contra la realidad, esto es, contra la llamada que dirigen a nuestro pensamiento y a nuestra atención todos los hechos por virtud de su existencia. Si respondiéramos siempre a tal llamada, pronto estaríamos exhaustos» (1977:4). En buena parte somos, pues, responsables del enmascaramiento del mundo por nuestra necesidad de simplificarlo, por no ser capaces de convivir mentalmente con su extrema complejidad: operamos dicha simplificación recubriendo la realidad con el velo de la ilusión, convirtiéndola en apariencia ilusoria. Pero hay más, y es que la articulación de nuestra experiencia, que no es sino lingüística incluso en el pensamiento, es también un factor de empobrecimiento, y correlativamente de deformación, de la realidad: la misma autora nos dice que «nada que veamos, oigamos o toquemos puede ser expresado en palabras que hagan justicia a lo que es dado a los sentidos» (1977:8), extendiendo así el aforismo de lo inefable de Wittgenstein a los objetos de la experiencia sensible, no sólo a lo que está más allá de ella. Habría, pues, en resumen, un triple origen de la apariencia: El natural (que genera las apariencias propiamente dichas que aquí nos interesan), el psicológico y el lingüístico. La realidad, de suyo, no es transparente ni inmediatamente cognoscible: conocemos inmediatamente de ella lo que ella presenta a nuestros sentidos; y a esta opacidad del mundo aparente añadimos tanto nuestras defensas en forma de prejuicios y simplificaciones, como nuestra incapacidad para expresar adecuadamente lo que de ella nos llega.

Afirma Marx en El Capital que «toda ciencia estaría de más, si la forma do manifestarse las cosas y la esencia de éstas coincidiesen directamente» (1972, III : 757); se sitúa, pues, Marx en la posición que parte de la diferenciación entre realidad y apariencia (la que Hannah Arendt llama «teoría de los dos mundos»), e incluso utiliza sin empacho la expresión esencia, y no por única vez: Como cuando señala que «el lienzo expresa real y verdaderamente su esencia propia de 
valor en el hecho de poder cambiarse directamente por la levita» $(1972$, I : 22), o cuando dice que ael valor no lleva escrito en la frente lo que es. Lejos de ello, convierte a todos los productos del trabajo en jeroglíficos sociales» $(1972$, I : 39). Hay, pues, que distinguir entre la realidad o esencia de la cosa y su apariencia o forma de manifestarse, ya que no coinciden directamente. $Y$ no sólo no coinciden, sino que con frecuencia se contradicen. Criticando las que llama «expresiones imaginarias», dice que éstas son "categorías en que cristalizan las formas exteriores en que se manifiesta la sustancia real de las cosas. En casi todas las ciencias es sabido que muchas veces las cosas se manifiestan con una forma inversa de lo que en realidad son; la única ciencia que ignora esto es la economía» (1972, I : 450). $E$ insiste en que con frecuencia algo «aparece velado», e incluso reviste "la apariencia contraria» (1972, I : 74): "Aunque el movimiento del dinero no hace más que reflejar la circulación de las mercancías, parece como si ocurriese lo contrario» (1972, I : 75). Y en otro momento, criticando a la economía vulgar, le reprocha que se aferre «a las apariencias contra la ley que rige los fenómenos» (1972, I : 245).

No se trata sólo, por tanto, de que la realidad de las cosas (su esencia o sustancia) y su apariencia (su forma exterior o manifestación) sean diferentes y puedan estar más o menos distantes, sino que muchas veces tal diferencia o distancia llega hasta el punto de que la apariencia sea contraria o inversa a la cosa real. Por ello la ciencia ha de ir más allá de la apariencia, hasta la cosa misma: refiriéndose a la determinación de la magnitud de valor por el tiempo de trabajo, dice Marx que ael descubrimiento de este secreto destruye la apariencia de la determinación puramente casual de las magnitudes de valor de los productos del trabajo» (1972, I : 40). El papel de la ciencia es, en efecto, descubrir lo secreto destruyendo la apariencia, lo que no siempre se consigue: «El gran mérito de la economía clásica consiste precisamente en haber disipado esta falsa apariencia y este engaño... Esto no obsta para que los mejores portavoces de la economía clásica... sigan en mayor o menor medida cautivos del mundo de apariencia críticamente destruido por ellos» (1972, III : 768).

Si la economía clásica consigue sólo a medias liberarse del engaño de las falsas apariencias, el caso de la economía vulgar es completamente diferente: «La aceptación sin crítica» de determinadas categorías brinda a la economía vulgar «una base segura de operaciones para su superficialidad, atenta solamente a las apariencias» (1972, I : 451). "La economia vulgar se encuentr(a) como el pez en el agua precisamente bajo la forma más extraña de manifestarse las relaciones económicas... estas relaciones apare(cen) tanto más evidentes cuanto más se esconde la trabazón interna entre ellas y más familiares son a la concepción corriente» ( 1972 , III : 757). La economía vulgar es, pues, «incapaz de aprender nada» (1972, I : 245), al contrario de la ciencia; su saber no es tal saber, pues no atiende sino a las apariencias y, al ser acrítica, no es capaz de destruirlas, sino que se mueve cómodamente entre ellas, tanto más cuanto que las apariencias tienen a su favor el resultar familiares a la concepción corriente, al sentido común. 
No hay, pues, que dejarse engañar por las apariencias engañosas; y no se trata de saltar sobre ellas o de, simplemente, destruirlas o disiparlas: hay que explicarlas. En opinión de Marx, «para analizar científicamente el fenómeno de la concurrencia hace falta comprender la estructura interna del capital, del mismo modo que para interpretar el movimiento aparente de los astros es indispensable conocer su movimiento real, aunque imperceptible para los sentidos» (1972, I : 245). Este importante texto manifiesta con toda claridad la convicción marxiana de que hay un plano externo, fenoménico, perceptible por los sentidos, que es o puede ser engañoso, y otro interno, real, que no es fenoménico en tanto que es imperceptible por los sentidos, y que es el que ha de desvelar la ciencia; de suerte que, descubierto su secreto, queda por ello mismo explicado el fenómeno engañoso. Hay que llegar hasta lo oculto analizando científicamente lo visible (no aceptándolo sin más), y explicar el jeroglífico de lo visible precisamente por lo oculto: «El imperio de las condiciones de producción sobre el productor queda oculto tras las relaciones de dominio y sojuzgamiento que aparecen y son visibles como los resortes in mediatos del proceso de producción» $(1972$, III : 769). Lo inmediato, visible y aparente pesa tanto sobre la concepción del observador corriente que lo considera «como algo necesario por naturaleza, lógico y evidente» (1972, I : 45): la ciencia ha de pugnar con el sentido común para despojar al fenómeno de la atribución de tales notas y poner de manifiesto que su evidencia es engañosa, mostrando que no es algo necesario, natural ni lógico, y permitiendo así a lo mediato, oculto y real ocupar su verdadero lugar.

Con todo este planteamiento lo que Marx establece, según Norman Geras, es "la condición mínima necesaria que ha de ser satisfecha por todo trabajo que aspire a un status científico: a saber, que descubra la realidad que existe detrás de la apariencia que la oculta»; se trata, pues, de «un requisito general para llegar a un conocimiento válido, requisito que (Marx) toma de otras ciencias donde ha sido establecido desde hace tiempo» (1977: 322-323). Pero Geras no se satisface con que Marx establezca un requisito general de la ciencia, de toda ciencia, sino que se pregunta por qué tal requisito es fundamental para la ciencia que Marx hace, y llega a la conclusión de que son las propiedades del objeto de estudio marxiano las que «exigen imperiosamente que las apariencias sean destruidas si la realidad ha de ser captada correctamente». Y ello porque la doctrina marxiana del fetichismo «analiza los mecanismos mediante los cuales la sociedad capitalista aparece necesariamente a sus agentes como algo diferente de lo que realmente es» (ibidem). La doctrina del fetichismo, en efecto, implica que en la sociedad capitalista determinadas realidades aparezcan necesariamente enmascaradas con una apariencia engañosa; pero, en mi opinión, la tesis de Marx al respecto está fundamentada en consideraciones más generales, como creo que queda claro de los textos de $\mathrm{El} \mathrm{Ca}$ pital que han sido transcritos más arriba. El caso del fetichismo es, por supuesto, el que con más fuerza impone aceptar la «teoría de los dos mundos», y volveré sobre él inmediatamente. Pero creo que no sólo en el supuesto del fetichismo, y no sólo en el de la sociedad capitalista, la apariencia engañosa como apariencia nece- 
saria exige al científico social una actitud crítica que permita llegar a la realidad de la cosa más allá del testimonio de los sentidos, destruyendo la apariencia sensible al explicarla por lo que estaba oculto y queda ahora desvelado. Es, pues, el objeto de conocimiento de las ciencias sociales el que impone tal concepción de la realidad y tal método: lo que especifica a las ciencias sociales respecto de «las otras ciencias" en este punto no es, contra lo que opina Geras, que se estudie la sociedad capitalista y que en ella se produzca el fenómeno del fetichismo; sino que, en mi opinión, toda realidad social se caracteriza porque, en primer lugar, tanto la realidad de la cosa como su apariencia engañosa producen efectos sociales reales (en tanto que en la realidad físico-natural la apariencia engañosa no produce ninguna clase de efectos físico-naturales reales); y, en segundo lugar, porque la propia realidad social contiene elementos (intereses e ideologías) que objetivamente sostienen la apariencia engañosa (en tanto que la realidad físico-natural es indiferente a cómo sea vista y valorada por el observador).

Pero volvamos con Geras, quien justamente señala que el fenómeno del fetichismo se impone a los hombres simultáneamente en forma de dominación (bien que encubierta e impersonal) y en forma de mistificación (1977: 324 ss.), aunque se cuida de señalar, como por mi parte vengo insistiendo, que no todas las apariencias o formas de manifestación de la cosa son engañosas, y que cuando lo son no se trata de ilusiones del sujeto (citando a este efecto a Maurice Godelier: «No es el sujeto el que se engaña, sino la realidad la que le engaña». Cf. 1977 : 334). En resumidas cuentas, para nuestro autor «es la propia sociedad capitalista la que se caracteriza por una cualidad de opacidad, de tal forma que es ella la que crea la necesidad de una metodología que penetre la apariencia para descubrir la realidad, y entonces, en sentido inverso, por decirlo así, demostrar por qué esta realidad ha de adoptar tal apariencia» (1977:338). En todo, pues, de acuerdo con Geras, salvo en limitar a la sociedad capitalista la opacidad y la existencia de apariencias necesarias. Es cierto, sin embargo, como precisa Lamo, que los análisis de Marx van en la dirección indicada: por ejemplo, «el paso del modo de producción feudal al capitalista es, en relación con el "modo de aparecer", el paso desde la transparencia al fetichismo y la mistificación» (Lamo, 1981:51); y recuerda que, para Marx, en el modo de producción capitalista la producción parece estar dirigida por leyes técnicas bajo el control de la naturaleza y de nuestro conocimiento de ella, cuando en realidad está basada en la división del trabajo; la distribución parece ser el resultado de un acuerdo social, cuando en realidad se apoya en la sacralización de la propiedad privada desigual de los medios de producción; el cambio parece resultado de acuerdos o contratos individuales y libres, siendo en realidad desigual y forzoso; y el consumo, aparentemente asunto de la libre voluntad individual, es en realidad una actividad determinada socialmente tanto en sus mínimos como en sus modos. Como recuerda Lamo, «cada momento del metabolismo social es algo distinto de lo que nos parece», y si la pretendida ciencia social atiende sólo a la apariencia con una actitud naturalista y descriptiva, se convierte en ideología, reproduciendo la realidad en su apariencia como dato construido socialmente, como 
lo socialmente dado (1981: 52 ); y desde luego todo esto es así en el modo de producción capitalista. Pero no sólo en él. No sólo en la sociedad capitalista la mistificación de la realidad actúa como factor de legitimación, sino en toda sociedad pasada o presente. Y no digamos futura para no cerrar la puerta a la utopía.

Las categorias de la ciencia que atiende sólo a las apariencias son, pues, categorías insuficientes para captar la realidad; como bien dice Lamo, «el camino de la ciencia es, para Marx, el camino que va de la apariencia (del sentido común, de la ideología como su reproducción) a la esencia»; pero ese camino «no es... un abandono de lo real en búsqueda de entidades metafísicas sino, al contrario, trascender la metafísica implícitamente positivista del sentido común para descubrir la praxis humana que produjo y conserva esa realidad». «Hay, pues, en la metodología de Marx una clarísima concepción de la necesidad de romper con la epistemología ingenua del sentido común para producir una construcción científica del objeto social» (1981:60-61). Y bueno será recordar que la apariencia no es un hecho de conciencia, sino que forma parte de la realidad en el sentido de que es real en sus efectos: la apariencia, construida socialmente y aceptada por el sentido común como realidad, es tan cosa como la cosa misma encubierta por ella, pues ambas operan en la realidad social, entendida ésta ahora como incluyendo realidades y apariencias, lo oculto y lo visible, lo mediato y lo inmediato. Pienso que esta realidad social así entendida constituye el objeto de la Sociología, por lo que si ésta quiere ser ciencia y no ideología habrá de atender a realidades y apariencias, yendo a las primeras a través de la superación crítica de las segundas, y explicando lo visible por lo oculto.

Se ha aludido varias veces en los párrafos anteriores a que las realidades y apariencias sociales son productos humanos. En efecto, y sin necesidad de entrar ahora en discusión con etólogos o biosociólogos, nada $\longrightarrow$ muy poco- en la sociedad humana es natural, y todo -0 casi todo- es histórico. La realidad social (incluyendo tanto realidades propiamente dichas como apariencias) es, pues, producto de la actividad social humana, no algo dado, natural o necesario. Esto lleva directamente al tema de la construcción social de la realidad, y con él al conocido libro de Berger y Luckmann de igual título (1968). No estará de más recordar que los autores parten del carácter dual de la realidad social, que es tanto facticidad objetiva como significado subjetivo: una realidad sui generis. Interesados por cómo los significados subjetivos se convierten en facticidades objetivas, llegan a la conclusión de que «la sociedad es un producto humano. La sociedad es una realidad objetiva. El hombre es un producto social» (1968:84). Conclusión que en sus propios términos es perfectamente aceptable, como vengo diciendo. Pero el problema surge cuando se trata de concretar lo que entienden los autores por «realidad objetiva»; no me voy a referir aquí al proceso de externalización, objetivación y posterior internalización de las prácticas sociales, pues algo de ello tengo dicho en otro lugar (cf. $1979: 173$ ss.); quiero limitarme a destacar aquí que la noción de realidad objetiva de Berger y Luckmann ha de ser tomada cum grano salis, y ello por varias razones. 
En primer lugar porque el término realidad se utiliza deliberadamente desprovisto de cualquier implicación respecto del ser de tal realidad: «El análisis fenomenológico de la vida cotidiana, o más bien de la experiencia subjetiva de la vida cotidiana, es un freno... contra las aserciones acerca de la situación ontológica de los fenómenos analizados» (1968: 37). Los autores, pues, ponen entre paréntesis qué sean tales fenómenos, e incluso sugieren expresamente que no se trata de fenómenos objetivos (o al menos externos), sino subjetivos. Evidentemente no tendría sentido entrar aquí en una discusión rigurosamente filosófica acerca del status ontológico de la realidad social, pero sí hay que indicar que los autores parecen manejarse con un concepto peculiar de realidad, que hace referencia sobre todo a experiencias subjetivas. Podría decirse que el título del libro sería más propiamen. te el de La construcción social del sentimiento subjetivo de que determinadas internalizaciones tienen realidad, utilizando una equivalencia expresamente formulada por los propios autores (cf. $1968: 179$ ).

En segundo lugar, y en estrecha relación con lo anterior, la realidad social que estudian los autores resulta ser un hecho de conciencia: «El mundo de la vida cotidiana no sólo se da por establecido como realidad por los miembros ordinarios de la sociedad... Es un mundo que se origina en sus pensamientos y acciones, y que está sustentado como real por éstos» (1968: 37). Una vez más lo externo cede ante lo subjetivo, por más que lo subjetivo se objetivice en el mundo intersubjetivo del sentido común (tema éste, el del sentido común, que exige volver sobre él de inmediato). El que la realidad social sea para Berger y Luckmann un hecho de conciencia es, por otra parte, perfectamente consecuente con la expresa orientación fenomenológica de su trabajo.

Todo esto lleva, a mi parecer, a la más importante objeción que puede hacerse al planteamiento que estoy comentando. Comparto la idea de que la realidad social está socialmente construida, y entiendo que lo mismo ha de predicarse de las apariencias sociales. Pero me temo que si para Berger y Luckmann la apariencia es experimentada subjetivamente como realidad, entonces es realidad pura y simple, no es apariencia, no encubre nada. Con lo que les resulta imposible distinguir entre realidades y apariencias (no en vano están por la fenomenología) y niegan implícitamente la existencia de ambos planos por separado. $Y$, efectivamente, la apariencia es «real» no sólo en el sentido subjetivo definido por los autores, sino en el más objetivo y externo, puesto que produce efectos en la realidad social como he dicho más arriba; pero el problema es que la realidad oculta a la que encubre dicha apariencia también produce efectos por su parte. La cosa y su apariencia, ambas, producen efectos objetivos y externos independientemente una de otra: en este sentido ambas forman parte de la realidad social, una como lo oculto, lo enmascarado, y otra como lo aparente, la máscara. Ambas, pues, han de ser tomadas en consideración por una ciencia de la realidad social que merezca tal nombre. $\mathrm{Y}$ sin embargo, entiendo que una de ellas, la realidad oculta o mediata, es dejada totalmente al margen por Berger y Luckmann, quienes en realidad atienden 
sólo a "la construcción social de la apariencia», esto es, de una parte de la realidad: precisamente de su parte engañosa.

En las páginas anteriores nos hemos tropezado varias veces con el tema del sentido común, y este es el momento de que nos detengamos brevemente en él, abordándolo por la vía de la cuestión que nos viene interesando, la de la realidad social. Nuestra certidumbre de que lo que percibimos tiene existencia objetiva, independiente de nosotros mismos, descansa en que el mismo objeto aparezca como tal a otros y sea reconocido por ellos. Como ha dicho Hannah Arendt, «no el Hombre, sino los hombres habitan este planeta. La pluralidad es la ley de la tierra» (1977 : 19): lo que yo veo lo ven otros, y ésta es la base de mi certeza. Sin embargo, todo lo que aparece se percibe bajo el modo lo-que-me-parece, y por tanto es susceptible de ser aprehendido de manera errónea o ilusoria; no obstante lo cual, la apariencia como tal comporta una fuerte sensación de realidad para el espectador. Esta sensación de realidad es el fundamento del sentido común (en su versión estricta de Aristóteles y de Tomás de Aquino), en virtud del cual se generalizan mis cinco sentidos privados a un mundo compartido con otros: el sentido común logra un mundo intersubjetivo en el que los objetos, ciertamente, pueden ser vistos desde diferentes perspectivas, pero como existentes y con el mismo contexto para todos. Hay, pues, un acuerdo de todos sobre la realidad e identidad de la cosa, que confirma la experiencia sensible que cada uno tiene del mundo. La realidad es, pues, algo dado para el sentido común, y esta sensación de realidad es tan biológica (procede de los sentidos) como social (es confirmada por los demás); en cualquier caso es estrictamente necesaria para sobrevivir, por serlo la certidumbre acerca de lo percibido.

El pensamiento, sin embargo, desconfía con frecuencia de la experiencia de los sentidos, y sospecha que a veces las cosas son diferentes de como aparecen ante aquéllos: esta capacidad crítica del pensamiento no es compartida por el sentido común, al que basta la confirmación de la experiencia compartida para darla por buena y descansar en ella. La objetividad del mundo del sentido común está construida, pues, sobre la pura subjetividad de la conciencia a través de la experiencia de la intersubjetividad.

Por otra parte, el sensus communis naturae (como diferente del estricto sensus communis aristotélico-tomista al que me he referido hasta aquí) denota, de acuerdo con los escolásticos, la idea de un «acuerdo universal» respecto de ciertos principios o verdades que se suponen aceptables para todos, acuerdo basado en la existencia de una naturae rationalis inclinatio propia del hombre. Se trata, pues, de una cualidad unificante cuyo objeto (nociones, verdades o principios) es percibido como evidente por sí mismo y compartido por todos en su evidencia, ya sea ésta de carácter cognitivo-teórico o ético-práctico. La Escuela Escocesa, especialmente Reid, Beattie y Stewart, al estudiar el fundamento del juicio, encuentra que hay en el hombre un locus principiorum que desempeña el papel de facultad que permite formular juicios no escépticos; el sentido común puede errar en cuestiones de hecho, pero no en cuestiones de principio (cf. Ferrater, 1979 : 977). El análisis del 
sentido común y de sus contenidos ha llegado a formas tan refinadas como la de G. E. Moore y su «realismo del sentido común», tratando incluso de determinar los criterios para reconocer si una determinada proposición pertenece al sentido común, a la categoría de las notiones communes.

Pues bien, tanto por lo que se refiere a la noción estricta del sentido común (percepción compartida de la realidad que la constituye como tal) como a la más amplia de establecimiento de nociones o principios igualmente compartidos, la cuestión está en que si su percepción de los objetos es tan acrítica que toma las apariencias engañosas poi realidades, entonces será necesario que un tipo de conocimiento más exigente y crítico, el conocimiento científico, rompa con el sentido común y se construya a espaldas suyas. Planteado de manera más cruda: ¿Es la ciencia un conocimiento diferente del sentido común? ¿Consiste esa diferencia, si es que existe, en que la ciencia no se deje engañar por las apariencias? $Y$ en el caso de que la ciencia sea capaz de saltar sobre las apariencias, ¿qué encuentra, y cómo lo encuentra, más allá de ellas?

Hannah Arendt, a quien tantas veces vengo recurriendo, no cree que la ciencia y el sentido común sean diferentes. En su opinión, «la ciencia no es sino una prolongación enormemente refinada del modo de razonamiento del sentido común, en el que las ilusiones de los sentidos son constantemente disipadas, del mismo modo que la ciencia corrige sus errores. El criterio en ambos casos es la evidencia que como tal es inherente a un mundo de apariencias»: se rechaza una evidencia sólo porque se adquiere otra evidencia que sustituya a la primera, según la famosa cadena puesta de manifiesto por Merleau-Ponty. Y la autora concluye: «La ciencia se mueve en el ámbito de la experiencia del sentido común, sujeto al error rectificable y al des-engaño" (1977:54). Es decir, que tanto el sentido común como la ciencia pueden tomar las apariencias engañosas por realidades verdaderas, y que uno y otra son capaces de rectificar sus errores cuando se aperciben de que habian tomado el rábano por las hojas. Y no se trata para nuestra autora, ciertamente, de que dé igual la ciencia que el sentido común: ya he citado su opinión de que la primera es una prolongación enormemente refinada del segundo, pero no otra cosa. Tan es así que «no importa cuán lejos hayan dejado las teorías científicas la experiencia y el modo de razonamiento del sentido común: deben finalmente volver a alguna forma de él, so pena de perder todo sentido de la realidad del objeto de la investigación» (1977: 56).

No son pocos quienes piensan de parecida forma. Recientemente Pérez Díaz ha roto también una lanza en favor del sentido común, negándose a la tesis de la ruptura, a la que me referiré de inmediato. Para Pérez Díaz (1980 : 123-145), entre ciencia y sentido común existe una homología fundamental que no elimina las diferencias, pero las reduce a diferencias de grado; una y otro se basan en la experiencia en general, que se constituye tanto en saber científico como en saber de sentido común. La objeción de que el sentido común no distinga entre apariencia y realidad no resiste un examen serio. Hay, pues, una relación de continuidad del saber vulgar con la ciencia. Incluso entre el lenguaje en que se expresa el sentido 
común y el lenguaje científico hay una correspondencia fundamental, particularmente cuando se trata de las proposiciones observacionales de las ciencias sociales, que no sólo se expresan en el lenguaje del sentido común, sino que formulan proposiciones de mero sentido común. El autor señala agudamente que en el caso de las ciencias sociales los científicos dialogan con un público que se considera con conocimientos suficientes para emitir un juicio razonable sobre lo que estos científicos hacen, con lo que el establecimiento de un lenguaje esotérico se hace imposible $\mathrm{y}$, de otro lado, el lenguaje vulgar se contamina con términos y expresiones de la jerga sociológica. Las gentes comunes disponen de una masa de experiencias, teorías, ideas generales, proposiciones, e incluso experimentos, sobre la sociedad en que viven infinitamente mayor que la de los científicos sociales: por eso éstos descubren constantemente, pero no con mayor precisión ni mejor fortuna, lo que ya está descubierto.

El descrédito del sentido común es una estrategia de la comunidad científica, que trata de hacerse valer frente al mundo de los profanos (y Pérez Díaz lleva a cabo un brillante análisis de un caso particular y más complejo de tal estrategia, el del cuerpo de profesionales del «saber marxista»; cf. particularmente pp. 138143, op. cit.). El autor resume su examen sosteniendo que «los argumentos contra el sentido común no son concluyentes, ni convincentes», y en todo caso pueden ser igualmente «aplicados contra la ciencia social y también aqui son insuficientes, sólo parcialmente ciertos»; no niega la distinción entre ciencia social y sentido común, pero subraya «la homología estructural básica entre una y otra forma de saber» y rechaza cualquier corte o ruptura epistemológica entre ambas (1980: 144-145).

La cuestión, y la expresión, de la coupure épistémologique procede de Gaston Bachelard, y aparece en su obra de 1938 La formation de l'esprit scientifique (1974). Para este autor, las teorías científicas tienen un carácter extremadamente complejo que refleja la variedad de estructuras de lo real y que es incompatible con todo tipo de simplificación y de pretensión de saber absoluto: a lo más que aspira la ciencia es a una suerte de "aproximativismo». El «corte epistemológico» implica la necesidad de una ruptura del espíritu científico con el pre-científico, entre los que no sólo no hay continuidad, sino que no son comparables; por ejemplo, los conceptos de que se vale la ciencia no tienen que ver con marcos de referencia no científicos, pero tampoco se derivan de la generalización de observaciones, sino de «observaciones cargadas de teoría» que están muy lejos de la observación del sentido común, ya que los hechos a que atiende la ciencia se constituyen como tales hechos sólo a través de la teoría, y no a la inversa. Para Bachelard, cuya influencia en autores como Foucault y Althusser es bien conocida, la experiencia científica contradice a la común, que es un obstáculo epistemológico; la ciencia ha de hacerse en contra del objeto y de las sensaciones que éste provoca.

Por su parte, Bourdieu y sus colaboradores ejercen de bachelardianos, particularmente en Le métier de sociologue (1977, e. o. de 1973), donde declaran que «la familiaridad con el universo social constituye el obstáculo epistemológico por 
excelencia para el sociólogon (1976:27), rechazando con ello la intersubjetividad del sentido común. El principio de la no-conciencia que formulan se basa en la tesis de que la vida social debe explicarse no por la idea que de ella se hacen sus participantes, sino por las causas profundas que escapan a la conciencia (1976:30). Como he indicado en otro lugar ( $1979: 385)$, la negación de lo subjetivo se fundamenta así en el rechazo del sentido común, de la experiencia inmediata, de la tentación de la explicación por lo simple, y del lenguaje común: todo ello proporciona sin mayores esfuerzos una apariencia de explicación, la ofrecida por la sociología espontánea de los no especialistas, llena de «buen sentido». Frente a tal aceptación de la evidencia del objeto inmediato, la ciencia social debe construir su objeto, rompiendo con los objetos preconstituidos por la observación ingenua y con la con. figuración del conocimiento como su mera comprobación. Los autores son, pues, en última instancia, fieles a los hechos, pero no a su apariencia. $\mathrm{Y}$ si reniegan de algo es del sentido común.

No todas las posiciones que desconfían del sentido común son tan radicales como las de Bachelard y Bourdieu que han sido aludidas. Gouldner, por ejemplo, destaca la formación histórica de la que llama "cultura del discurso crítico», caracterizada por justificar sus aserciones, por no hacerlo apelando a autoridades o a la posición social del hablante, y por obtener la aquiescencia de sus destinatarios gracias a la argumentación y sólo a ella. El lenguaje de la cultura del discurso crítico es relativamente ajeno a la situación, independiente del contexto y de su variabilidad (1980: 48-49); por consiguiente, tal cultura es muy diferente de la del sentido común, y «a menudo diverge de los supuestos fundamentales de la vida cotidiana y tiende a ponerlos en tela de juicio» (1980:15). Ciertamente, Gouldner no está aquí estableciendo los caracteres de la ciencia, sino sólo los de la variante lingüística elaborada que es propia de la que llama «Nueva Clase», esto es, los intelectuales y la intelligentsia técnica. Pues bien, si la gramática del discurso a que se refiere está lejos del sentido común, es evidente que la ciencia propiamente dicha lo estará más todavía: ciencia y sentido común encarnan dos modos de saber, dos culturas del discurso, que tienen poco que ver entre sí. Especialmente cuando, como Gouldner dice en otro lugar (1978: 60), «la definición social de Lo Que Es se convierte en una cuestión política, pues se relaciona con la cuestión de cuáles grupos son subordinados y cuáles dominantes, y por lo tanto, influye en lo que cada uno obtiene. Los "informes" sobre Lo Que Es son modelados por las estructuras de dominación social -especialmente por el crédito que comúnmente se otorga a las definiciones de la realidad social de la élite-». La realidad que existe para el sentido común es, pues, el resultado de una determinada relación de dominación, y en concreto de los intereses de los dominantes; frente a tal situación, y frente a las ideologías que no se limitan a conocer la realidad, sino que tratan de remediarla, las ciencias sociales afirman explícitamente su superioridad cognoscitiva; en mi opinión, de manera muy dudosa cuando pretenden fundamentarla en una pretendida neutralidad valorativa, que no sólo me parece imposible sino, desde cierto punto de vista, indeseable. Pero cuando las ciencias sociales argumentan en su 
favor tal superioridad cognoscitiva frente al sentido común, parece que debiera dárseles la razón. Pues el que la definición de la realidad utilizada por el sentido común pueda estar, y esté, mediada por las relaciones de dominación y, en definitiva, manipulada o impuesta por quienes dominan, hace necesario volver la vista a la ciencia social, la cual podrá estar evidentemente aquejada del mismo mal, pero cabe suponer que no con el mismo grado de indefensión. Pero este argumento no nos aleja de la posición mantenida por Pérez Díaz, a saber, la continuidad entre los planos de la ciencia y el sentido común, cuya distancia es meramente una cuestión de grado. $Y$ ello incluso aunque se ponga de manifiesto la debilidad del sentido común ante la presión del poderoso: son (es de notar) Berger y Luckmann quienes reconocen que «las definiciones de la realidad social pueden ser impuestas por la policía, lo que... no tiene por qué significar que tales definiciones seguirán siendo menos convincentes que las que se aceptan "voluntariamente": el poder en la sociedad incluye el poder de determinar procesos decisivos de socialización $\mathrm{y}$, por lo tanto, el poder de producir la realidad» $(1968: 152)$. Y volvemos a lo mismo: la indefensión del sentido común contrasta a este respecto con la resistencia de la ciencia a aceptar definiciones impuestas brutalmente; pero desdichadamente incluso la ciencia (o lo que pese a todo se ha seguido llamando ciencia) ha sucum. bido ante la presión cuando ésta ha sido demasiado fuerte. Luego la cuestión es de grado.

Pero de que entre la ciencia y el sentido común exista una homología básica que reduzca sus diferencias a diferencias de grado (tesis de Pérez Díaz), o de que la ciencia no sea sino una prolongación enormemente refinada del sentido común (tesis de Hannah Arendt), no se sigue que la primera no tenga que oponerse al segundo, construyéndose incluso contra él. $O$ más exactamente: construyéndose contra lo aceptado intersubjetivamente como dado y la seguridad que de ello se desprende. Dicho en otras palabras: la Sociología no puede ignorar el saber común acerca de la sociedad, pero ese saber común forma parte precisamente de su objeto de estudio, y como tal ha de ponerlo en cuestión. Tanto más cuanto que ese mismo término, común, no puede entenderse en modo alguno como universal: por muy común que sea en una sociedad dada el sentido común (sobre todo en su aspecto de notiones communes), siempre estará fragmentado en varias subculturas (en más o en menos según el grado de complejidad y de diferenciación social de la sociedad de que se trate). Es de esperar que una serie de contenidos del sentido común sean efectivamente comunes a todos ( $y$ en esa medida se podrá hablar de la existencia de una cultura), pero cabe la posibilidad de que ese «techo cultural» común sea bastante limitado si la riqueza y la autonomía de las subculturas existentes son lo bastante intensas (a causa de tensiones históricas, o de la profundidad de las líneas de fractura social, o de la fuerte diferenciación geográfica, o del diferente grado de evolución económica, etc.). Cuando hablamos, pues, del sentido común referido a algo más que a la sensación de realidad de los objetos físicos percibidos por los sentidos, hay que recordar que se trata de un sentido común con contenidos; y que si bien el fenómeno del sentido común es como tal común a todas las sub- 
culturas existentes en un ámbito cultural más amplio, no así sus contenidos, que pueden contrastar llamativamente. El saber social del sentido común es mucho menos común y más fragmentario de lo que pudiera parecer.

Por otra parte, y recordando cuántas veces se equipara (por el sentido común) sentido común a «buen sentido», conviene indicar que los escolásticos pecaban de optimistas al suponer a la naturaleza humana poseedora de una sólida inclinatio rationalis. Sería ridículo negar que tal disposición existe, pero lo sería igualmente ignorar cuán azarosamente florece en el hombre la planta de la razón, y cuánto cuido y atención necesita. Debe admitirse, pues, la posibilidad de que el sentido común esté inspirado por la recta razón, pero también debe admitirse que no sea así. Y no creo que sea exagerado sostener que la probabilidad de que la razón anide con más facilidad en la ciencia que en el sentido común es más alta que su contraria.

No parece que deba discutirse que tanto el sentido común como la ciencia pueden dejarse engañar por las apariencias: pero aunque el propio sentido común sostenga que las apariencias engañan, lo suyo es lo inmediatamente evidente, esto es, la apariencia, lo-que-me-parece. Bien es verdad que existen planteamientos científicos que por garantizar la objetividad se niegan a ir más allá de lo externamente observable, con lo que asumen ciertos riesgos de tomar el velo por lo velado, lo visible por lo oculto. Pero, en general, no cabe duda de que el sentido común se queda con más facilidad en la apariencia engañosa, y que la ciencia es menos proclive a tal limitación: al menos parece profesionalmente dispuesta a seguir la cadena de apariencias de Merleau-Ponty con las refinadas prolongaciones de los sentidos que tiene a su disposición (aunque eso no lo resuelva todo, ya que no sale de lo puramente empírico: pero ése no es problema de este momento).

Por último, que el sentido común está marcado por la ideología dominante, esto es, por la ideología de quienes son socialmente dominantes, parece bastante obvio. Es cierto que, por lo mismo que el sentido común no es nunca rigurosamente común, su coloración por la definición de la realidad que interesa a quienes dominan no será nunca universal ni absoluta; pero no es menos cierto que, sin nccesidad de utilizar a la policía, la élite dispone de medios mucho más sutiles e igualmente eficaces de imponer su definición de la realidad (aunque sea en pugna con otras definiciones alternativas); lo que, si posible, siempre resultará extremadamente más difícil en el caso de la ciencia.

Me ha parecido necesario repasar los anteriores argumentos, nada refinados por cierto, para situar la discusión en el punto que me interesa, el de establecer la relación existente entre sentido común y realidad social. Pues bien, quisiera insistir en dos cosas que me parecen esenciales. Por una parte, y respecto a la capacidad del sentido común para habérselas con la realidad, conviene recordar que la intersubjetividad que lo caracteriza no equivale en modo alguno a objetividad: la intersubjetividad es subjetividad compartida que, por serlo, produce la sensación de realidad que tan necesaria es para la vida. Sensación de realidad que, cuando la realidad aparece encubierta por una apariencia engañosa (lo que tantas veces sucede en la vida social), consagra el engaño de modo que resulta particular- 
mente difícil librarse de él. Por otra parte, el hecho de que exista un saber de sentido común acerca de la realidad, y específicamente de la realidad social, no hace sino añadir un elemento más al objeto de la ciencia social, y una nueva necesidad de explicación a su tarea; y obsérvese que si, como dije más arriba, tanto la realidad como su apariencia engañosa constituyèn el objeto de la Sociología y demandan la pertinente explicación, es justamente el sentido común el locus privilegiado de las apariencias: lo que la gente piensa de la sociedad en la que vive no es necesariamente ni una visión totalmente objetiva ni tampoco totalmente mistificada de tal sociedad; pero es claro que objetividad y mistificación forman parte, a menudo de manera inextricable, del saber de sentido común que la propia sociedad genera y transmite.

Para Murillo, el saber de sentido común sobre la sociedad, o saber vulgar, desde el punto de vista lógico es asistemático (por más que posea la articulación interna derivada de su relación con el sistema de creencias de la sociedad de que se trate), y puede ser calificado de existencial, ya que responde a situaciones vitales y tiene por objeto hacer posible la vida en común; se trata, además, de un saber que mezcla criterios puramente fácticos con otros valorativos. Este saber social espontáneo e indispensable puede ser rechazado por el científico social (a través de una suerte de «ignorancia consciente», dice Cuvillier) por entender que obstaculiza el conocimiento científico de la sociedad; pero, en opinión de Murillo, «este saber vulgar tiene también una dimensión positiva, y consideramos necesario incluir entre las preocupaciones de la Sociología de nuestro tiempo su análisis sistemático, pues es lo que la sociedad sabe de sí misma» (1958:268). El saber de sentido común tiene pocas cualidades especulativas, pero posee una gran importancia social pues, tanto si es un saber de realidades («verdadero») como de aparien» cias («falso»), condiciona el comportamiento efectivo de la gente. Ahora bien, en la medida en que los estudiosos de la sociedad producen saber científico sobre ella, irá teniendo lugar una cierta transformación del mismo en saber vulgar: si «la Sociología ofrece al hombre ordinario explicaciones racionales y científicas de las pautas de la vida en común», «el saber espontáneo e impersonal se verá sustituido cada vez más por el saber reflexivo elaborado por los sociólogos» (1958:269). ¿Cómo afectará este proceso al funcionamiento de los resortes de la vida colectiva? Esta pregunta es una invitación a explorar la que podríamos llamar «otra cara» de la Sociología del conocimiento, que si suele limitarse a estudiar el condicionamiento social del saber, tendría que preocuparse también del condicionamiento intelectual de la vida social, tanto por el saber científico en general como por el sociológico en particular.

Volviendo al tema de las apariencias, el sentido común se presenta como ambivalente, pues no sólo acoge, e incluso crea, apariencias engañosas otorgándoles el estatuto de objetividad que les proporciona la intersubjetividad; sino que también previene contra las apariencias, con frecuencia sin éxito, y a veces las destruye. El sentido común tanto se engaña como se des-engaña. Por otra parte, que el sentido común sea el ámbito privilegiado de las apariencias engañosas no quiere decir en modo alguno que sea el único ámbito de ellas: las apariencias no se dan sólo en lo que la gente piensa o dice, sino también en lo que la gente bace. Los propios 
objetos, los hechos, las conductas, los procesos, las situaciones sociales de todo tipo pueden parecer una cosa y ser en realidad otra, totalmente al margen de lo que la gente piense o diga al respecto. Realidad y mistificación son, pues, tanto fenómer nos mentales como materiales, por llamarles así.

Pues bien, este tema de lo mental y lo material viene reclamando nuestra atención en relación con el objeto de la Sociología, y ha producido una copiosa discusión, de la que no podemos tomar sino algún botón de muestra. Un famoso texto de Edwar Sapir, de 1927, recogido por Harris, reza como sigue:

Es imposible decir qué está haciendo un individuo a menos que hayamos aceptado tácitamente los modos de interpretación esencialmente arbitrarios que la tradición social nos sugiere constantemente desde el mismo momento de nuestro nacimiento. A cualquiera que dude de esto puede dejársele que intente hacer un cuidadoso informe acerca de las acciones de un grupo de nativos ocupados en alguna actividad, digamos religiosa, respecto de la que el observador no disponga de sus claves culturales. Si es un escritor habilidoso puede tener éxito en lograr una descripción pintoresca de lo que ve y oye; o piensa que ve y oye; pero sus posibilidades de dar cuenta de lo que sucede de una forma que sea inteligible y aceptable para los propios nativos son prácticamente nulas. Incurrirá en toda clase de distorsiones, y su énfasis estará constantemente desviado; encontrará de interés lo que los nativos consideran carente de interés, y fracasará por completo en la identificación de los puntos cruciales de la acción que dan significado formal al conjunto de la misma en las mentes de aquellos que tienen la clave de su comprensión (apud Harris, $1969: 570.571$ ).

Dicho de otra manera, lo que verdaderamente importa para dar razón de la actividad en cuestión no es cómo la ve el observador «desde fuera», sino cómo la ven los nativos (obsérvese la terminología colonialista-antropológica) «desde dentro»: la comprensión de la actividad requiere estar al tanto de las claves culturales que permiten entenderla. Si el observador externo no dispone de ellas, «no habrá entendido nada», no habrá sabido captar la realidad de lo observado. La realidad, para ser identificada, ha de ser comprendida, y sólo lo será en la medida en que lo sea a través de la mente de los participantes (de «los nativos»). Lo verdaderamente importante para el objeto de la ciencia social es «el punto de vista del nativo», en expresión ahora de Malinowski; para éste, aprehender tal punto de vista es el objetivo último del científico social (apud Harris, 1969 : 597). Podría decirse, pues, que para los partidarios de esta posición la realidad social radica de manera fundamental en la mente de los miembros de la sociedad de que se trate, hasta el punto de que su dictamen sobre la inteligibilidad y aceptabilidad del informe científico es lo que constituye a éste como tal. $\mathrm{Y}$ es de notar que dicha posición, con planteamientos más o menos nítidos, tiene una larga tradición que se remonta hasta la filosofía de Windelband o Dilthey, y que atiende permanentemente a la necesidad de alcanzar el significado que las acciones tienen para los actores en ellas implicados. 
En contraste con lo anterior ha de situarse el conocido y vigoroso texto de Marx y Engels en La ideología alemana:

Totalmente al contrario de lo que ocurre en la filosofía alemana, que desciende del cielo sobre la tierra, aquí se asciende de la tierra al cielo. Es decir, no se parte de que los hombres dicen, se representan o se imaginan, ni tampoco del hombre predicado, pensado, representado o imaginado, para llegar, arrancando de aquí, al hombre de carne y hueso; se parte del hombre que realmente actúa $y$, arrancando de su proceso de vida real, se expone también el desarrollo de los reflejos ideológicos y de los ecos de este proceso de vida... No es la conciencia la que determina la vida, sino la vida la que determina la conciencia. Desde el primer punto de vista, se parte de la conciencia como del individuo viviente; desde el segundo punto de vista, que es el que corresponde a la vida real, se parte del mismo individuo real viviente y se considera la conciencia únicamente como $s u$ conciencia $(1970: 26-27)$.

Lo que los hombres dicen, se representan o se imaginan no puede ni debe constituir el punto de partida del conocimiento; por el contrario, el conocimiento terminará explicando la conciencia individual como un reflejo o eco de la vida real, esto es, de lo que la gente hace realmente. Lo que importa, pues, no es lo que la gente piensa o dice, sino lo que la gente hace. Y precisamente no se explica lo que hace por lo que dice, sino al contrario. Aquí no se acredita el trabajo del científico gracias a que parezca inteligible o aceptable a los observados: será, por el contrario, el científico quien explique desde fuera la mentalidad de los observados. Es la vida (externa) quien explica la conciencia (interna), la tierra quien explica el cielo. La realidad que ha de ser objeto de estudio de la ciencia social no es, pues, la que se ve desde "el punto de vista del nativo», sino desde el punto de vista del científico.

Planteadas así las cosas, entiendo que no debe aceptarse la oposición entre las tesis reseñadas como una alternativa entre posibilidades científicas mutuamente excluyentes, porque una y otra tomadas aisladamente mutilan de manera intolerable la realidad social: la primera, porque confina al investigador en el universo mental de los sujetos que constituyen el objeto de estudio, y le impide ver la realidad externa desde su propio punto de vista; la segunda, porque veda el acceso a dicho universo mental, y fuerza al investigador a limitarse a una realidad externa que puede resultarle, efectivamente, carente de sentido.

La realidad externa tiene un sentido para la gente que participa en ella. La realidad social como tal no se agota en lo externo, sino que requiere ser completada con el sentido que sus participantes le atribuyen, y es esta realidad más compleja, simultáneamente externa y mental, la que interesa al sociólogo. No le interesa sólo lo externo o sólo lo mental: uno y otro forman parte de su objeto de conocimiento, de la realidad social. Y ello porque ambos planos tienen consecuencias en la propia realidad social (recuérdese que se trata del mismo argumento, el de los efectos, que cuando concluía páginas atrás que tanto la realidad en sentido estricto como su apariencia engañosa forman parte de la realidad social): esta es otra pe- 
culiaridad del objeto de la Sociología, la de tener un plano «interno» o mental y otro "externo" o material que han de considerarse conjuntamente y que se explican mutuamente (otra cuestión es si se determinan entre sí y en qué dirección, a lo que ya contestan Marx y Engels en el texto citado más arriba; pero me parece que no es cosa de entrar en ello ahora).

Volvamos, pues, al tema de la realidad y la apariencia. Ahora puedo, según creo, insistir con mayor fundamento en que la apariencia y la realidad se dan tanto en lo que la gente dice como en lo que la gente hace, tanto en el plano mental como en el del comportamiento. Uno y otro son partes complementarias de la realidad social, y en ambos pueden presentarse las cosas tal como son o veladas por apariencias engañosas. Lo que la gente piensa, cree, siente y dice acerca de la vida social puede ser tanto una apreciación objetivamente correcta como una mistificación (a veces involuntaria y a veces consciente, pero siempre por razones sociales). Del mismo modo, el actuar de la gente en sus relaciones sociales puede revelar de manera objetiva lo que sus relaciones sociales son, o puede, por el contrario, encubrir o disimular lo que son, de suerte que parezcan otra cosa: que parezcan otra cosa incluso al propio actor, con lo que se corresponderán una mistificación objetiva y otra subjetiva; o que parezcan otra cosa sólo al observador externo, siendo el actor consciente - al menos en un cierto grado- de la mistificación objetiva.

Esta complejidad del juego de, por una parte, realidad y apariencia y, por otra, los planos mental y material, me lleva a considerar excesivamente simplificadora la llamada de atención de Sylos Labini en contra de una concepción de la realidad de tipo pirandelliano: Così è se vi pare (1976 : VIII). En efecto, las cosas no son de cierta manera porque así le parezcan a la gente, sino que son como son; pero no es indiferente que, siendo efectivamente como son, le parezcan a la gente de una manera $u$ otra, pues ello comporta determinadas consecuencias.

Una de ellas, harto conocida, es la que se recoge en el llamado teorema de Thomas, bajo la formulación divulgada por Merton, de que «si los individuos definen las situaciones como reales, son reales en sus consecuencias». Para Merton, «los hombres responden no sólo a los rasgos objetivos de una situación, sino también, y a veces primordialmente, al sentido que la situación tiene para ellos. $Y$ así que han atribuido algún sentido a la situación, su conducta consiguiente, y algunas de las consecuencias de esa conducta, son determinadas por el sentido atribuido» (1964 : 419). Merton se había ocupado ya de un aspecto del problema en su trabajo de 1936 "The Unanticipated Consequences of Social Action» (recogido ahora en $1976: 145-155$ ), en el que se refería, entre otras cuestiones, a las que llamó self-defeating predictions: el supuesto es el de que «las predicciones públicas de futuros eventos sociales frecuentemente no se cumplen precisamente porque la predicción ha pasado a ser un nuevo elemento de la situación concreta, tendiendo así 7 cambiar el curso de los acontecimientos inicialmente previsto» $(1976: 154)$. El principio de la «profecía que se frustra a sí misma» podría explicar, por ejemplo, por qué determinadas predicciones de Marx no han llegado a cumplirse. El mismo Merton volvió más tarde sobre un aspecto complementario del tema en su artículo de 1948 «The Self-fulfilling Prophecy» (recogido en $1964: 419-434$ ), en el que sostiene paralelamente a su trabajo anterior que «las definiciones públicas 
de una situación (profecías o predicciones) llegan a ser parte integrante de la situación, y en consecuencia, afectan a los acontecimientos posteriores... La profecía que se cumple a sí misma es, en el origen, una definición falsa de la situación que suscita una conducta nueva, la cual convierte en verdadero el concepto originariamente falso» (1964: 420-421); la creencia, pues, engendra la realidad. Tanto la self-defeating como la self-fulfilling pueden ser predicciones vulgares o científicas; vulgares serían, por ejemplo, la creencia en la falta de solidez de un Banco (que la produce), o la suposición de que en un día y horas determinados la «operación retorno" a una gran ciudad producirá grandes retenciones de tráfico (que las impide); en el caso de predicciones científicas estarían no sólo las marxianas antes aludidas, sino todo el conocimiento científico sobre la sociedad, que reflexivamente causa impacto sobre ella. Y así se pregunta Murillo: "¿Cuál será la conducta de los hombres cuando los procesos sociales hayan sido iluminados por el análisis científico suficientemente divulgado?» (1958:266). Desde luego que no será la misma que antes de tener tal información: la definición de multitud de situaciones habrá cambiado, y con las nuevas definiciones las conductas, y con ellas sus consecuencias. Lo que implicará, evidentemente, autocumplimiento y autofrustración de muchas predicciones, que de falsas pasarán a ser verdaderas, y viceversa.

Pero quizá Merton ha limitado en su análisis el planteamiento de Thomas a las consecuencias futuras de una definición, cuando en realidad la cuestión no se plantea sólo hacia el futuro (così sarà), sino en el presente (così è): las definiciones de la realidad social tienen permanentemente consecuencias en la realidad social, y ello tanto si se trata de definiciones «verdaderas» (fieles a la realidad) como «falsas» (acogedoras de su apariencia engañosa). No se trata sólo, repito, de profecías que se cumplan o frustren por el hecho de formularse y divulgarse, modificando así el curso que el futuro hubiera seguido de no existir la profecía. De lo que se trata, como fenómeno más general, es del funcionamiento cotidiano del presente, que se ve afectado tanto por las definiciones de la situación ajustadas a la realidad como por las tributarias de su apariencia engañosa. Este es el sentido que tiene para mí el teorema de Thomas: que lo definido como real, séalo o no, produce consecuencias reales; pues la propia definición pasa a formar parte de la situación y determina o condiciona las conductas de los implicados en ella. Las apariencias sociales, tanto como la estricta realidad, tienen efectos en la vida social a través de las definiciones que de ellas se hacen como reales. Y debe notarse que en la vida cotidiana (profecías aparte) producen efectos simultáneamente la realidad y su apariencia engañosa, lo enmascarado y su máscara: Efectos independientes, ora paralelos ora contradictorios.

$\mathrm{Ha}$ de estarse de acuerdo con Sylos Labini en rechazar el que llama mito pirandelliano; en efecto, las cosas no son así porque así nos parezcan. Pero ese parecer no es modo alguno indiferente, porque forma parte, él también, de la realidad social, a la que influye, condiciona o determina, tanto en el plano diacrónico de predicciones sobre el futuro que se cumplen o se frustran por el hecho de formularse y divulgarse, como en el plano sincrónico del estricto presente. Las cosas son, de hecho, de una forma, y sin embargo algunas de ellas son percibidas de otra por la gente, que ajusta su conducta a su percepción a través de la definición equivot 
cada que hacen de la situación. Y es importante destacar que la percepción de que se trata no es estrictamente individual e independiente, sino que está socialmente condicionada $o$, con más propiedad, mediada socialmente. Las distorsiones aparienciales de la realidad social no se producen al azar o por puras razones de inmediatez subjetiva, aunque tampoco ha de pensarse que respondan mecánicamente a ciertas determinaciones: el problema es con seguridad extremadamente complicado, y no es mi propósito entrar ahora a discutir los procesos y mecanismos de la percepción de la realidad social. Baste negar, como vengo negando con todo lo dicho, cualquier teoría especular que tratase de ignorar la existencia y el papel de las apariencias engañosas junto a la realidad propiamente dicha, así como sus consecuencias en la vida social.

Pero volvamos por un momento a las dos posiciones que más arriba se ejemplificaban con textos de Sapir y de Marx y Engels; he dicho respecto de ellas que no me parece que haya que optar por una u otra, dado que no son excluyentes sino complementarias: ambas recogen aspectos diferentes de la realidad (el mundo mental de quienes, siendo sujetos, son sin embargo objetos de conocimiento; y el mundo externo tal como es observado por el investigador). Pues bien, de uno y otro mundo puede elaborarse ccnocimiento científico, y ello bajo dos modalidades diferentes: emic y etic, como son denominadas en los campos de la antropología y la lingüística, que es donde más se ha difundido tal distinción.

Los términos en cuestión fuercn acuñados por el lingüista Kenneth Pike en 1954, derivando «emic» de fonemic y «etic» de fonetic, y su uso fue generalizado sobre todo por Marvin Harris, a quien sigo en este punto, siendo actualmente términos y perspectivas relativamente usuales: valga por todos el ejemplo del muy conocido manual de Sociología del lenguaje de Fishman (1975). Pues bien, las proposicicnes «emic» hacen referencia a sistemas lógico-empíricos construidos con criterios que son juzgados como significativos, con sentido, reales, precisos, apropiados y aceptables por los propios actores (por «los nativos» de Sapir y Malinowski); la perspectiva «emic», por tanto, lleva a cabo el estudio de la realidad social en términos de las intenciones, propósitos, motivos, fines, actitudes, pensamientos y sentimientos de los actores, tal como son expresados y entendidos por ellos mismos (Harris, $1969: 571.575$ ). Desde esta perspectiva se describe la realidad social a través de categorías y relaciones isomórficas con las que los actores consideran apropiadas o significativas ( $1969: 580$ ), aunque el planteamiento «emic» no trata sólo de describir las prácticas scciales, sino de entenderlas junto con, y a través de, las creencias en que se apoyan: se trata, pues, de una posición empática, enraizada en la tradición idealista (1969:597). Salta, pues, a la vista que «la descripción de un participante acerca de lo que está realmente sucediendo... nọ tiene por qué corresponder a lo que el etnógrafo ve o vería en la misma situación" (1969 : 581). Expresión que me permito extremar como sigue: la descripción de un participante acerca de lo que está realmente sucediendo a juicio de los implicados no tiene por qué corresponder a lo que el investigador ve que está realmente sucediendo a su propio juicio. Con lo que queda de manifiesto la desazonante situación de que hay dos descripciones, posiblemente incompatibles, que reclaman la 
patente de decir qué es la realidad y qué la no-realidad, la apariencia. Lo que nos lleva de la mano al planteamiento «etic».

Las proposiciones «etic» son construidas con criterios juzgados como apropiados por la comunidad de observadores científicos, y deben permitir que observadores independientes utilizando procedimientos similares lleguen a los mismos resultados. La descripción de la realidad que se lleva a cabo desde el modo "etic» opera con categorías elaboradas de espaldas a los actores, en el lenguaje del investigador, y sin que tenga ningún interés el sentido o falta de sentido que dichas categorías revistan para los protagonistas.

Ambas perspectivas, «emic» y «etic», son opciones perfectamente legítimas desde el punto de vista científico, y no puede pensarse que una («etic») sea más objetiva y otra («emic») más subjetiva. Como dice Harris,

Ser objetivo no consiste en adoptar un punto de vista etic, ni ser subjetivo uno emic... Es claramente posible ser objetivo - esto es, científicotanto respecto de fenómenos etic como emic. Del mismo modo, es igualmente posible ser subjetivo tanto respecto de unos como de otros. La objetividad es el status epistemológico que distingue a la comunidad de observadores de la comunidad que es observada... Objetividad no es meramente intersubjetividad. Es una forma especial de intersubjetividad establecida por la disciplina lógica y empírica a la que los miembros de la comunidad científica acuerdan someterse $(1980: 34-35)$.

Por tanto, son posibles las dos perspectivas (el punto de vista del nativo y el punto de vista del investigador) siempre que se lleven a cabo de acuerdo con los cánones de la disciplina científica.

Bien es verdad que en su libro de 1980, Cultural Materialism, Harris ha modificado sensiblemente la posición que mantuvo en el de 1969, The Rise of Antbropological Theory. En éste, el modo «etic» se desentendía del sentido que las prácticas sociales pudieran tener para sus protagonistas a causa de que el universo de significados, propósitos, fines y motivaciones de la gente le era inaccesible: trabajar sobre los fenómenos mentales era algo completamente ajeno a la perspectiva «etic», limitándose ésta, por tanto, a los fenómenos externos, conductuales (cf. 1969 : 575 y 580 ss.); la segunda característica de tal perspectiva era -y sigue siendo- la de que las categorías y criterios utilizados para el estudio han de ser los compartidos por la comunidad científica, sin que necesiten ser considerados inteligibles y apropiados por «los nativos». En cambio, en el libro más reciente se afirma ya que «los pensamientos y la conducta de los participantes pueden ser vistos desde dos diferentes perspectivas: Desde la de los propios participantes, y desde la de los observadores. En ambas instancias es posible dar cuenta científicamente -esto es, objetivamente- de los campos mental y conductual. Pero en la primera instancia, los observadores emplean conceptos y distinciones significativos y apropiados para los participantes, en tanto que en la segunda lo son para los observadores» (1980:31). Así, pues, tanto el universo mental interno de los acto- 
res como su universo conductual externo pueden ser estudiados científicamente desde las dos perspectivas «emic» y «etic»: la única diferencia radica ahora en que en el caso de un estudio «emic», sea de fenómenos mentales o externos, los conceptos y criterios utilizados son los de los propios actores; en tanto que en un estudio «etic» son los de la comunidad científica. $Y$ en ambos casos lo que garantiza el carácter objetivo o científico de la investigación es el sometimiento de la misma a los cánones de disciplina lógica y empírica válidos en la comunidad cien. tífica.

Me interesaba detenerme en la evolución de la posición mantenida por Harris por lo que implica respecto de la concepción de qué sea la realidad social y cómo estudiarla: el modo «emic» no se limita ya a los fenómenos mentales y el «etic» a los conductuales, pues unos y otros forman parte de la realidad social a la vez mental y conductual, y en la que, como hemos visto, el sentido otorgado por los actores a sus acciones y la definición que hagan de la situación tienen efectos sobre la realidad en la medida en que ajusten a ellos sus acciones. No es que la realidad sea como les parece a sus participantes (aunque pueda, efectivamente, terminar siéndolo), sino que tanto la realidad que es como la que parece que es producen consecuencias sobre la propia realidad. Ambas, pues, realidad y apariencia, han de ser tenidas en cuenta por el estudioso de la realidad social, y ambas se dan tanto en el mundo mental como en el conductual, en lo que la gente piensa como en lo que la gente hace. La aportación final de Harris y de quienes con él distinguen entre una perspectiva «emic» y otra «etic» consiste así en la apelación al sentido común para la construcción de la primera, tomando de él los conceptos, categorías y distinciones que han de utilizarse para describir y eventualmente explicar la realidad.

Y me parece que esto tiene gran importancia para las ciencias sociales, ya que, por una parte, todo el mundo sabe muchas cosas acerca de la sociedad en la que vive y - ¿por qué no? - de la sociedad en general: todo el mundo es un poco «sociólogo», tanto más cuando, como hemos visto, la terminología y los trabajos de los sociólogos profesionales han alcanzado una sorprendente difusión social; por otra parte, los propios sociólogos profesionales han construido en buena parte la Sociología utilizando materiales conceptuales y terminológicos que han tomado prestados del saber social de sentido común, haciendo así un trabajo «emic» sin saberlo. Y me temo que en esta interacción entre sentido común y Sociología no siempre se ha prestado suficiente atención a la distinción entre apariencia y realidad, y cuando se ha hecho ha sido para despreciar la primera (por las corrientes «desenmascaradoras») o la segunda (por las que se niegan a ver más allá de lo que se ve), o para identificar apariencia con mundo mental o con sentido común y realidad con mundo conductual o externo. Pues bien, mi conclusión, por lo que queda dicho, es que la realidad social en sentido amplio, como objeto de conocimiento de la Sociología, tiene que incluir tanto las realidades en sentido estricto como sus apariencias, unas y otras dándose tanto en las mentes de la gente como en sus actividades: y ello por la razón de que realidades y apariencias, tanto en la mente como en el mundo externo, tienen consecuencias para la vida social. La realidad social con que ha de habérselas la Sociología incluye elementos mentales (parte de 
los cuales es fiel a la realidad y parte a su apariencia) y elementos conductuales externos (que en parte revelan lo que es y en parte lo ocultan); y creo que si se intenta simplificar esta realidad social por estimar excesiva su complejidad, se la mutila y falsifica de manera inaceptable. Alguien pensará que lo que afirmo puede ser cierto, pero que no es viable porque implica tratar de estudiarlo todo a la vez, y si se parte de que todo es importante y de que todo tiene consecuencias en todo no se progresará mucho en el conocimiento. Pero tal objeción, con ser de peso, debe esperar a que demos un paso más en la delimitación del objeto de conocimiento de la Sociología, a saber: cuál sea el contenido de la realidad social.

Trataré de concluir estas reflexiones volviendo al planteamiento básico que reivindica la distinción entre realidad y apariencia, o esencia y apariencia, de la mano ahora de Adorno, para quien «negar que haya una esencia equivale a tomar partido por la apariencia», lo que es tanto como «dar el mismo valor a todos los fenómenos»; el rechazo de la esencia para atenerse estrictamente al fenómeno, a la apariencia, está motivado las más de las veces por el temor a los desvaríos metafísicos que, so capa de ir a lo esencial saltando sobre el fenómeno, puedan poblar el conocimiento de ídolos. Pero adoptar tal postura equivale para Adorno a «hacer causa común con la mentira por un amor fanatizado a la verdad»: «El positivismo se convierte en ideología cuando elimina primero la categoría objetiva de esencia y luego, consecuentemente, el interés por lo esencial». Por otra parte, la apariencia no es el resultado de una deficiente percepción por parte del sujeto:

Lo que media los hechos no es tanto el mecanismo subjetivo que los preforma y concibe, como la objetividad heterónoma al sujeto tras la que éste pueda experimentar. Ella escapa al círculo subjetivo primario de la experiencia, le está preordenada. Siempre que al nivel histórico actual se juzga, como se suele decir, demasiado subjetivamente, el sujeto se hace eco del consensus omnium, la mayoría de las veces automáticamente. Sólo si en vez de conformarse con el falso molde resistiera a la producción en masa de una tal objetividad y se liberara como sujeto, sólo entonces daría al objeto lo suyo. De esta emancipación depende hoy la objetividad y no de la insaciable represión del sujeto. El predominio de lo objetivado en los sujetos, que les impide llegar a ser tales, impide, asimismo, el conocimiento de lo objetivo (1975: 173).

Asperas palabras, pues no se echa fácilmente de ver cómo el sujeto podrá desoír el consensus omnium, el sentido común que produce la objetividad social, y precisamente por «la precedencia de la sociedad ante la conciencia individual y toda su experiencia» (1975: 183). La apariencia, como he repetido ya, no está puesta por el sujeto: al menos, la apariencia social que interesa a la Sociología está puesta bien por el propio objeto, bien por el común de la sociedad; con lo que la pretensión de eliminar lo subjetivo del sujeto para alcanzar lo real no resolvería gran cosa. Como señala Adorno,

el comienzo de la Crítica de la razón pura presupone la prioridad de la conciencia, prioridad que a su vez debe delimitar a la ciencia; pero esa prio- 
ridad es deducida con criterios metódicos que confirman o rebaten los juicios según normas científicas. Tal círculo vicioso delata un planteamiento falso. Por de pronto encubre que los datos de la conciencia no tienen en sí nada de puro, indubitable o absolutamente primero... Pero hay más... Lo cierto es que no hay sujeto alguno de los datos inmediatos, o yo al que le sean dados, que pueda hacerse independiente del mundo transubjetivo (1975: 197).

No hay, pues, posibilidad de un a priori que permita eludir el hecho universal de la mediación; y si incluso se afirma la prioridad del objeto, resulta que está mediado él mismo. La única salida, por tanto, no puede consistir sino en una crítica de la realidad social capaz de discernir entre realidad y apariencia, por muy articulada, compartida y comprobada que la apariencia se presente, y por muy lejana, chocante e incomprobable que la realidad sea. «De apariencia necesaria sólo puede hablarse socialmente refiriéndose a algo que no fuese apariencia, a pesar de ser accesible a través de ella» (1975: 198): lo que implica la necesidad de afirmar como real algo que no aparece, y de negar la realidad de algo que aparece. Tal actitud comporta el riesgo de tomar lo imaginario como real, aunque también aligera el peligro de dar la apariencia engañosa como real: ¿Podrá la Sociología evitar caer en aquel riesgo y en este peligro?

En todo caso, séame permitido mostrar mi acuerdo con Marvin Harris cuando sostiene que «debemos ciertamente intentar entender por qué la gente piensa que se comporta tal como lo hace, pero no debe bastarnos tal comprensión. Es necesario que nos reservemos el derecho a no creer sus explicaciones. Y sobre todo debemos reservarnos el derecho a no creer las explicaciones de la clase dominante» (1980 : 340); pues al hacerlo terminaríamos identificando la verdad con el poder. $\mathrm{Y}$ eso es justamente lo que la Sociología debe tratar de evitar.

\section{REFERENCIAS}

Adorno, Theodor W. (1975): Dialéctica negativa, Madrid: Taurus (e. o. de 1966).

ARENDT, Hannah (1977): The Life of the Mind. Vol. One: Thinking, New York: Harcourt Brace Jovanovich.

Bachrand, Gaston (1974): La formación del espiritu científico, Buenos Aires: Siglo XXI (e. o. de 1938).

Beltran, Miguel (1979): Ciencia y Sociologia, Madrid: Centro de Investigaciones Sociológicas.

Bergm, Peter L., y Luckmnn, Thomas (1968): La construcción social de la realidad, Buenos Aires: Amorrortu (e. o. de 1966).

Bourdieu, P.; Chamboredon, J. C., y Passeron, J. C. (1976): El oficio de sociólogo, Madrid: Siglo XXI (e. o. de 1973).

Frarntan Morn, José (1979): Diccionario de Filosofia, 4 vols., Madrid: Alianza Editorial.

Fishmax, Joshua (1975): The Sociology of Language, Rowley: Newbury House.

Geras, Norman (1977): "Marx y la crítica de la economia politica", en Robin BrackBURN (ed.): Ideologia y ciencias sociales, Barcelona: Grijalbo.

GOULDNER, Alvin W. (1978): La dialéctica de la ideología y la tecnología, Madrid: Alianza Iditorial.

- (1980): El futuro de los intelectuales y el ascenso de la nueva clase, Madrid: Alianza Bditorial. 
HARRIS, Marvin (1969): The Rise of Anthropological Theory, London: Routledge and Kegan Paul.

- (1980): Cultural Materialism: The Struggle for a Science of Culture, New York: Random House.

Lamo de Espinosa, Emilio (1981): La teoría de la cosificación. De Marx a la Escuela de Francfort, Madrid: Alianza Editorial.

MarX, Karl (1972): El Capital, 3 vols., México: Fondo de Cultura Económica (e. o. de 1867,1885 y 1894).

MaRX, Karl, y Engels, Friedrich (1970): La ideologia alemana, Barcelona: Grijalbo (e. O., MEGA, de 1932).

Merton, Robert K. (1964): Teoría y estructura sociales, México: Fondo de Cultura Económica (e. o. de 1949).

- (1976): Sociological Ambivalence and other Essays, New York: The Free Press.

Murillo, Francisco (1958): "L'impact sociologique dans la société", en Institut International de Sociologie, Actes du XVIIIe. Congrès International de Sociologie, Verlag Anton Hain KG, Meisenheim am Glan.

Pérez Diaz, Víctor Miguel (1980): Introducción a la sociología, Madrid: Alianza Editorial.

Sylos Labini, Paolo (1976): Saggio sulle classi sociali, Bari: Laterza. 